\title{
The Xmrk Oncogene Promoter is Derived from a Novel Amplified Locus of Unusual Organization
}

\author{
Dorothee Förnzler, ${ }^{1,3}$ Joachim Altschmied, ${ }^{1,4}$ Indrajit Nanda, $^{2}$ \\ Renate Kolb, ${ }^{1}$ Monika Baudler ${ }^{1}$, Michael Schmid, ${ }^{2}$ and \\ Manfred Schartl ${ }^{1}$
}

\author{
${ }^{1}$ Physiological Chemistry I, Theodor Boveri Institute for Biosciences (Biocenter), ${ }^{2}$ Department of Human \\ Genetics, University of Würzburg, 97074 Würzburg, Germany
}

\begin{abstract}
Hereditary melanoma in Xiphophorus hybrids is caused by the receptor tyrosine kinase Xmrk. Tumor formation is initiated by overexpression of the Xmrk gene, apparently because of insufficient transcriptional control in the melanocytic lineage of hybrid fish. The oncogenic Xmrk resulted from gene duplication and nonhomologous recombination of the corresponding Xmrk proto-oncogene during evolution. By this event Xmrk was translocated downstream of the promoter of another gene, $D$ (for Donor). This raised the question whether both the Xmrk oncogene and $D$ share similar transcriptional control elements. Studies on the genomic organization of $D$ showed that this gene is amplified in the Xiphophorus genome, presumably with all copies clustered on a single chromosome. Surprisingly, at least two completely different, tightly linked genes are included in the amplified segment. We find a ubiquitously expressed zinc finger gene of the krüppel type, followed by a previously unknown gene, which was the partner of the Xmrk proto-oncogene in the recombination generating the Xmrk oncogene. The nucleotide sequence predicts a gene product with very high amino acid similarity to a hypothetical Caenorhabditis elegans protein. The expression pattern is unrelated to that of the Xmrk oncogene suggesting that despite extended sequence homology a new type of promoter was created by this rearrangement.
\end{abstract}

In Xiphophorus fish certain hybrid genotypes spontaneously develop malignant melanoma. Responsible for this melanoma formation is the receptor tyrosine kinase Xmrk (Wittbrodt et al. 1989). Several cellular receptor tyrosine kinases are known to play a role in human malignancies either after activation of the corresponding proto-oncogenes by translocation, mutation, amplification, and subsequent overexpression, or as transforming genes in the genomes of retroviruses. However, Xmrk was the first case, where it was shown that an activated oncogene is passed through the germ line without being harmful to the organism. A comparable situation has been described recently in humans in multiple endocrine neoplasias type $2 \mathrm{~A}$ and $2 \mathrm{~B}$ and familial medullary thyroid carcinomas. Here, mutations in the gene for the receptor-like tyrosine kinase

\footnotetext{
3Present address: Brigham \& Women's Hospital, Harvard Medical School, Boston, Massachusetts 02115.

${ }^{4}$ Corresponding author.

E-MAIL yogi@biozentrum.uni-wuerzburg.de; FAX 49-9318884150 .
}

RET convert the proto-oncogene into a dominant transforming gene, which can be transmitted through the germ line (Santoro et al. 1995). Thus, the Xiphophorus melanoma system might serve as a model for analyzing the mechanisms by which a deleterious gene is stably maintained in the genetic material and how germ-line transmission is facilitated. In the Xiphophorus genome, the Xmrk gene is present in two different copies, both located on the sex chromosomes. All individuals of the genus investigated so far carry the protooncogenic version of the gene. However, the oncogenic Xmrk locus is only present in those fish, such as the platyfish Xiphophorus maculatus, that exhibit specific pigmentation patterns marked by a peculiar cell type, the macromelanophores. After crossing with another Xiphophorus species, such as the swordtail Xiphophorus helleri, that has neither macromelanophores nor the Xmrk oncogene, benign and malignant melanoma originating from the macromelanophore spots appear in the offspring generations. In the parental platy- 
fish, spontaneous melanoma formation generally does not occur, owing to the presence of a tumor suppressor locus $R$, thus far uncharacterized, that counteracts the oncogenic activation of Xmrk. This locus is unlinked to the Xmrk oncogene and can segregate from it. This leads to benign melanoma in progeny with one $R$ locus still present, and to malignant melanoma, when $R$ is completely absent (for review of the Xiphophorus melanoma system, see Altschmied and Schartl 1994).

Although the nucleotide sequences of both Xmrk copies are 99\% identical (Adam et al. 1991), the expression patterns of the Xmrk protooncogene and oncogene are completely different. The proto-oncogene is expressed at low levels in a number of nontumorous tissues and in melanomas, without any correlation with the severity of the phenotype. In contrast, the Xmrk oncogene is expressed exclusively in melanoma and its expression depends on the absence of the tumor suppressor gene $R$. The expression level correlates positively with the state of malignancy.

It has been shown that the Xmrk protooncogene and oncogene differ in their 5'promoter regions (Adam et al. 1993). This can be explained by a gene duplication of the ancestral $\mathrm{X} m r k$ proto-oncogene. During the course of this event the new Xmrk copy was translocated downstream of the promoter of a different gene locus $D$ ( $D$ for Donor), resulting in the creation of the oncogene. This suggested that in the wild-type fish, which never develop melanoma, the $D$-derived oncogene promoter is transcriptionally controlled, either directly or indirectly, by $R$. Elimination of the suppressor $R$ following genetic segregation can lead to overexpression of Xmrk and to melanoma formation. Thus, it appears that the tumor suppressor function of $R$ is an accidental side effect of the transcriptional regulation that $R$ normally exerts on $D$ (Schartl 1995).

This hypothesis for $D$ and the Xmrk oncogene raises the following questions: Are the promoters still functionally equivalent, that is, do the genes have similar expression patterns? Or did the gene duplication create a novel, unrelated transcriptional control region that directs a unique expression pattern to the oncogene, namely, exclusively in macromelanophores of hybrid fish? The knowledge of the structure of the $D$-locus gene product and its expression could give additional clues as to why the Xmrk oncogene is out of proper transcriptional control in melanoma.
We show here that $D$ is not a single-copy gene in the Xiphophorus genome but is an amplified locus that is clustered on a single chromosome. In addition, the $D$ locus contains at least two structurally unrelated genes, one that encodes a zinc finger protein of the krüppel type, and one that contains an open reading frame (ORF) identifying a novel putative protein, which in some domains is highly conserved throughout evolution. Both of their expression patterns do not match that of the Xmrk oncogene.

\section{RESULTS}

\section{Amplification and Chromosomal Localization of the $D$ Locus}

In the initial experiments that identified the $D$ locus, it appeared that this could be a multicopy sequence (Adam et al. 1993). For a more detailed analysis, genomic DNA from various Xiphophorus genotypes and species was digested with different restriction enzymes and the size-fractionated DNA was hybridized with a $0.3-\mathrm{kb}$ fragment derived from the Xmrk oncogene promoter region that had been isolated previously and is identical to $D$ (Adam et al. 1993) and a 0.4-kb fragment directly upstream. The results clearly show that the $D$ locus contains an amplified gene. The fragments detected with the $0.3-\mathrm{kb}$ probe seem to be located in a conserved core region of this amplified gene locus, therefore revealing only a few, but strongly hybridizing bands (Fig. 1A). In contrast, the upstream flanking region shows high intraspecific variability (Fig. 1B). Hybridization was also obtained with DNA from a different strain of Xiphophorus maculatus, X. helleri, and the $X$. xiphidium-derived embryonic epithelial cell line A2 (Kuhn et al. 1979), all of which do not carry the Xmrk oncogene in their genome. This indicates that the presence of the $D$ locus is not restricted to fish with a genetic predisposition to melanoma formation. In an analysis of 89 individuals from 8 purebred species and 21 interspecific hybrids of various genotypes, we have not found a single genotype without a $D$ locus. A rough estimate based on the number of bands and signal strength in Figure $1 \mathrm{~B}$ shows that the Xiphophorus genome contains $\geqslant 20$ copies of the $D$ locus. Similar results were obtained using a $0.6-\mathrm{kb}$ probe from the $3^{\prime}$ end of the previously characterized 2.1-kb EcoRI $D$ locus fragment (data not shown).

To isolate $D$ locus genomic sequences a $X$. maculatus library was screened at high stringency 


\section{FÖRNZLER ET AL.}

A

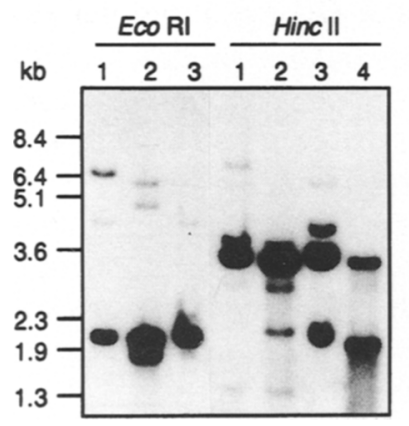

B

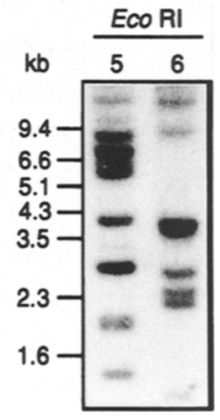

Figure 1 Amplification of the $D$ locus. $(A)$ Conservation of the core region. Genomic DNA from PSM cells (lane 1 ), A2 cells (lane 2), X. helleri (lane 3 ), and $X$. maculatus (lane 4, pool of DNAs without Xmrk oncogene and DNAs with the Sp, Sd, and Sr allele) was digested with the indicated restriction enzymes and the Southern blot was hybridized with the 0.3$\mathrm{kb}$ fragment from the $\mathrm{X} m r k / D$ promoter. The filter was washed with $0.1 \times \mathrm{SSC}, 1 \% \mathrm{SDS}$, at $68^{\circ} \mathrm{C}$. (B) Variability of flanking regions. Genomic DNA from $X$. maculatus carrying the $\mathrm{X}$ mrk oncogene $\mathrm{Sd}$ and $\mathrm{Sr}$ alleles (lane 5) or without the Xmrk oncogene (lane 6) was digested with EcoRI and the Southern blot was hybridized with the 0.4-kb fragment from the $\mathrm{X} m r k / \mathrm{D}$ promoter directly upstream of the conserved EcoRI fragment shown in Fig. 2. The filter was washed with $0.1 \times S S C, 1 \%$ SDS, at $68^{\circ} \mathrm{C}$.

with the $0.3-\mathrm{kb} X m r k / D$ promoter fragment. Four different phages were isolated, all of which contained the EcoRI promoter fragment diagnostic for the $D$ locus (Fig. 2A). Outside of this region they are markedly different. All further investigations were done using the phage $\mathrm{D} 2$, which contains about equal stretches of DNA $5^{\prime}$ and $3^{\prime}$ to the putative promoter region (Fig. 2B).

To study the arrangement of the multiple $D$ locus copies, fluorescent in situ hybridizations (FISH) on Xiphophorus mitotic and meiotic chromosomes were performed (Fig. 3). These experiments demonstrated that, at least within the detection limits of this method, all copies of the amplified unit colocalize in one cluster on a single chromosome.

\section{Evolutionary Relationship Between D and Xmrk}

To obtain more information about the diversity of the members of the $D$ gene family and especially about the sequences potentially controlling the transcription of these genes, we isolated promoter fragments from $X$. maculatus genomic DNA using a PCR approach. This amplification yielded three different promoter sequences in addition to the corresponding fragments from the four phages. All sequences are highly homologous but clearly distinct (Fig. 4). In a parsimony analysis the evolutionary relationship between the different $D$ gene promoters and the corresponding Xmrk oncogene sequences was established. Included in this analysis was the region between position -625 and -13 relative to the Xmrk transcriptional start site; D1 was omitted, because the available sequence is $350 \mathrm{bp}$ shorter. Independent of the chosen outgroup, Xmrk always branches off within the tree of $D$ sequences and clusters with D16 (bootstrap values $>90 \%$ ). This clearly indicates that the recombination event between $D$ and Xmrk took place after the amplification of the $D$ locus.

\section{Expression of Two Different Genes within the D Locus}

Knowing that the different $D$ copies have different promoters we set out to study the expression pattern of these genes. For transcript mapping, all four EcoRI fragments of the D2 phage were used as probes in Northern analyses. Whereas the 3.0-kb fragment does not identify a transcript, the results of analyses using the other three fragments suggest that two different genes are included in the D2 phage clone. At least three different transcripts with sizes of $1.8,3.1$, and $3.6 \mathrm{~kb}$ could be detected with the 3.5-kb EcoRI fragment under stringent conditions in nearly all adult tissues, in RNA of A2 cells, and in the Xiphophorus melanoma cell line PSM (Wakamatsu 1981), with a particularly high expression in brain, testes, A2, and PSM RNA (Fig. 5). In contrast, the $2.1-\mathrm{kb}$ EcoRI probe, which should contain part of the $D$ promoter-associated transcript, showed a very restricted pattern of expression: A $4.5-\mathrm{kb}$ transcript was found in liver and a 3.1-kb transcript in testes (Fig. 6). Weak expression of a $2.2-\mathrm{kb}$ transcript in melanoma of backcross hybrids was found only in 1 of 10 tumors. In addition, we see differential regulation of expression during embryonic development with a peak in embryos of stages 21 and 22 (data not shown). The expression pattern in adult tissues observed with the D2 6.2-kb EcoRI fragment is identical to the $2.1-\mathrm{kb}$ probe, however with a reduction in band intensity. These differences in the expression pattern between the 
UNUSUAL ORGANIZATION OF A GENE CLUSTER IN FISH

A

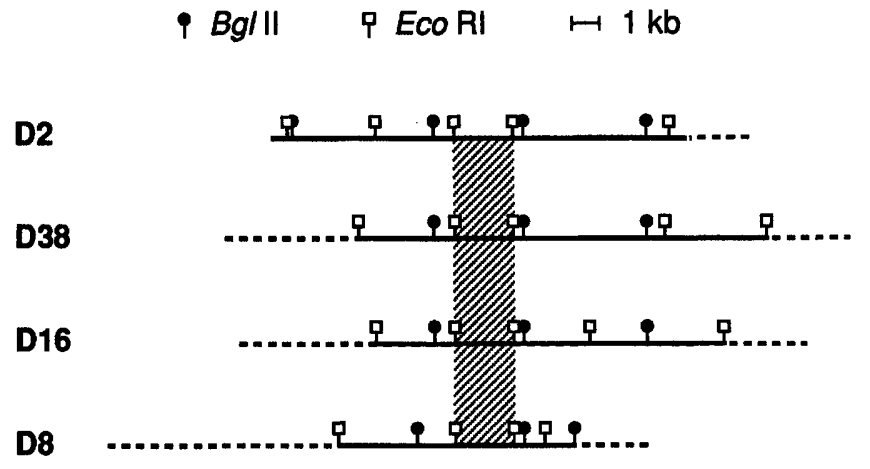

B

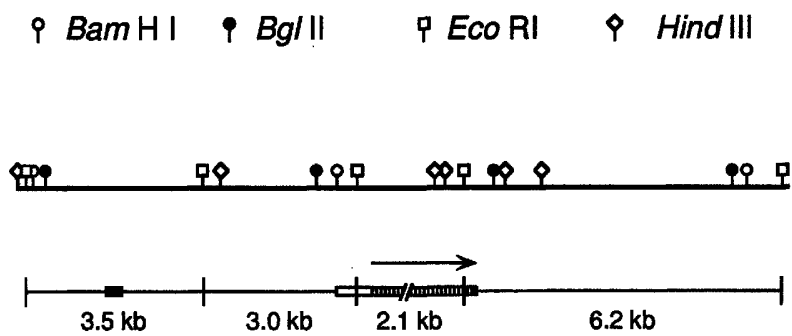

Figure 2 (A) Genomic organization of four $D$ genes. The restriction maps for the enzymes Bglll and EcoRl of four different $D$ locus phages are shown. The broken lines indicate fragments that could not be ascribed to a particular phage end with certainty. The hatched box covers the 2.1-kb EcoRI fragment common to all phages, which contains the previously characterized $D / X m r k$ oncogene breakpoint region. (B) Restriction map of the $D$ locus phage D2 for the enzymes BamHI, Bg/lI, EcoRI, and HindllI. The open box covers the region of the $D / \mathrm{X} m r k$ oncogene-promoter homolog, and the direction of transcription from this promoter is indicated by the arrow. The striped box represents the coding region of the corresponding $D$ gene, whereas the solid box designates the krüppel-type zinc fingers. The numbers at the bottom show the sizes of the EcoRI fragments.

RNAs detected with the 3.5- and 2.1-kb EcoRI fragments of D2 suggest that this locus contains at least two different transcription units.

Sequence analysis of the $3.5-\mathrm{kb} E c o \mathrm{RI}$ fragment revealed the coding potential for a zinc finger protein of the krüppel type (Fig. 7). We found the typical amino acids for a $\mathrm{Cys}_{2} / \mathrm{His}_{2}$ zinc finger and, in addition, extremely high conservation in the interfinger spacer (TGEKPFS), which is a hallmark of the krüppel subfamily of zinc finger proteins (Schuh et al. 1986). A data base search revealed highest homology on the nucleotide level to a human zinc finger gene on the $\mathrm{X}$ chromosome (ZNF-75, Villa et al. 1992), which codes for a member of the KRAB subfamily of multifingered proteins (Bellefroid et al. 1991; Villa et al. 1993).
The 2.1-kb EcoRI fragment of the D2 clone contains the $D / X m r k$ promoter sequences and lies 3' of the zinc finger gene. When this was used to screen a X. maculatus liver cDNA library under conditions of moderate stringency, a $1.6-\mathrm{kb}$ cDNA clone was isolated, containing an ORF of $1.1 \mathrm{~kb}, 345 \mathrm{bp}$ of $5^{\prime}$-, and $140 \mathrm{bp}$ of $3^{\prime}-$ untranslated sequences. The ORF can be translated into a 367 amino acid protein with a predicted molecular mass of 42.7 $\mathrm{kD}$ with no homologies to zinc finger proteins. We termed this polypeptide HASI based on a stretch of amino acids within the ORF. A data base search detected $42.1 \%$ amino acid identity over 140 amino acids (38.1\% over 202 amino acids) to a hypothetical Caenorhabditis elegans 32.1-kD protein ( $\mathrm{F} 54 \mathrm{H} 12.3)$ on chromosome III (Wilson et al. 1994). Additionally, there are a number of conservative amino acid exchanges within this domain (Fig. 8).

\section{DISCUSSION}

Detailed characterization of the gene locus $D$ involved in the evolution of the $\mathrm{X} m r k$ oncogene, which induces melanoma formation in backcross hybrids of Xiphophorus, revealed the multicopy nature of this locus. From the restriction analyses we deduce that this gene family contains $\geqslant 20$ members and is also present in species that do not carry the Xmrk oncogene. This is in agreement with Southern blotting data from Woolcock et al. (1994). In addition, we find that a core region of this amplified locus is structurally conserved even among different species, whereas the upstream flanking region is highly variable already within one species. After isolating the genomic region containing the amplified locus $D$, we could show that the amplified unit extends into a region far upstream of the hitherto characterized promoter sequences common to the Xmrk oncogene and the $D$ locus.

In situ hybridizations to Xiphophorus chromosomes demonstrate that all of the copies are clustered on a single chromosome, an organization that has been detected in all poeciliid fish species investigated so far (I. Nanda, S. Weiss, D. Förnzler, J. Altschmied, M. Schartl, and M. 


\section{FÖRNZLER ET AL.}
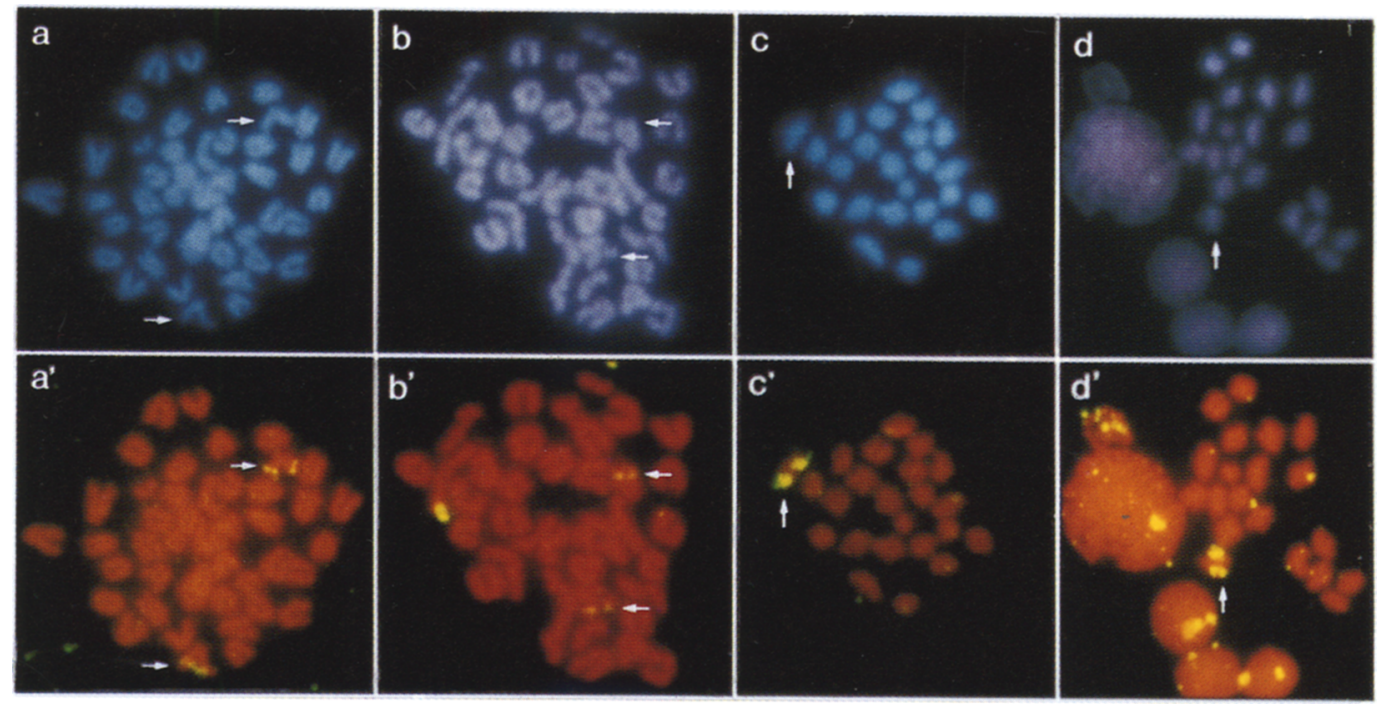

Figure $3 \mathrm{FISH}$ of the D2 $3.5-\mathrm{kb}$ EcoRI fragment to mitotic $\left(a^{\prime}, b^{\prime}\right)$ and meiotic $\left(c^{\prime}, d^{\prime}\right)$ chromosomes from $X$. maculatus and the corresponding DAPI stains of the chromosomes $(a-d)$.

Schmid, in prep.). The results concerning the chromosomal organization of the $D$ genes are in contrast to Woolcock et al. (1994), who claimed that these repeated sequences are equally distributed on several autosomes. However, we cannot exclude that besides the identified major cluster, a few additional orphan $D$ genes, which escape the detection by FISH, are located on other $X i$ phophorus chromosomes. The model for the evolution of the Xmrk oncogene suggests a nonhomologous recombination between the $D$ locus and the Xmrk proto-oncogene. According to such a model, the $D$ locus and the Xmrk oncogene should be colocalized initially on the same chromosome. At present, we do not know whether the Xmrk oncogene and the identified $D$ cluster still comap to one chromosome or have been separated in the course of the following evolution of the fish.

We have shown that the amplification of the $D$ locus gene cluster precedes the recombination event between one $D$ locus gene and the Xmrk proto-oncogene creating the Xmrk oncogene. This is in accordance with the observation that several other fish species show amplification of these sequences (I. Nanda, S. Weiss, D. Förnzler, J. Altschmied, M. Schartl, and M. Schmid, in prep.).

Transcript mapping revealed that the amplified region contains at least two completely different genes, which are tightly linked in the genome. One of these codes for a zinc finger protein of the $\mathrm{Cys}_{2} / \mathrm{His}_{2}$-type, with an interfinger spacer region identical to proteins of the kriuppel subfamily. It is likely that this is a nucleic acid binding protein and thus a putative regulatory molecule. Our assumption is based on the homologies to other genes of this family, the products of which bind to RNA or DNA or which have been implicated in the control of tissue-specific gene expression. However, it should be noted that the zinc finger gene we isolated from Xiphophorus is peculiar in one aspect. We find a tyrosine residue in the zinc finger loop, where all of the other proteins known so far contain a highly conserved phenylalanine (Jacobs 1992), indicating that the $D$ zinc finger gene might represent a new subtype. The relationship with ZNF75 already indicated that the $D$ locus zinc finger protein could be a multifingered molecule. Addi-

Figure 4 Comparison between eight $D$ gene promoters and the Xmrk oncogene $S d$ allele promoter (J. Altschmied, J. Duschl, and M. Schartl, unpubl.). The various $D$ gene promoters were isolated via PCR from $X$. maculatus Sd/Sr genomic DNA $(G 4, G 16)$ or from $X$. maculatus without the Xmrk oncogene (G29) and the four $D$-locus phages (D2, D8, D16, D38). D1 is a published sequence (Adam et al. 1993). Only nucleotide exchanges are indicated; dashes represent gaps that were introduced for optimal alignment. The TATA box of the Xmrk promoter is underlined. 
UNUSUAL ORGANIZATION OF A GENE CLUSTER IN FISH

D8
D16
D38
D2
G29
D1
G4
G16
Xmrk

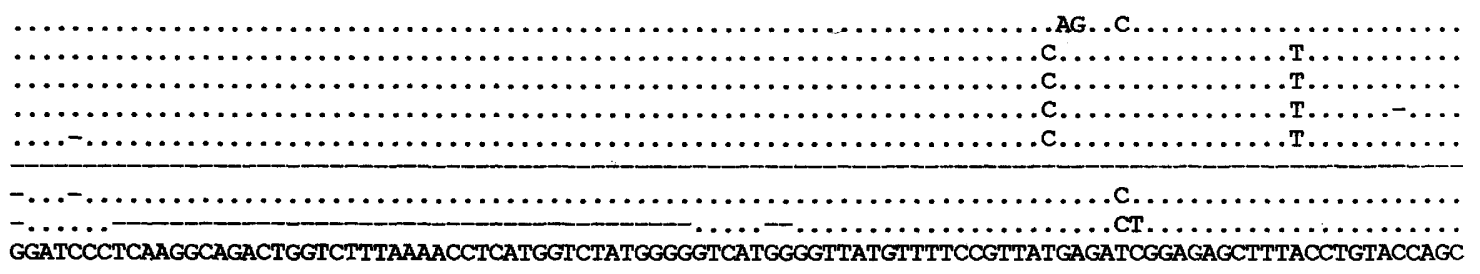

D8

D16

$\mathrm{D} 38$

G29

G4

G16

Xmrk

D8
D16
D38
D2
G29
D1
G4
G16
$\mathrm{D} 8$

D16

D38

D2

G29

G16

Xmrk

D8
D16
D38
D2
G29
D1
G4
G16
Xmrk

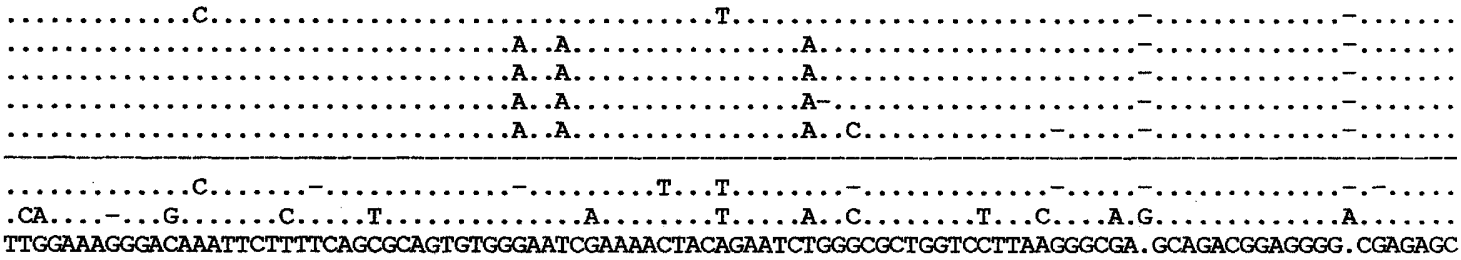

G

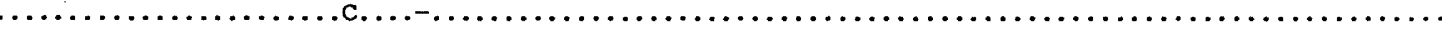

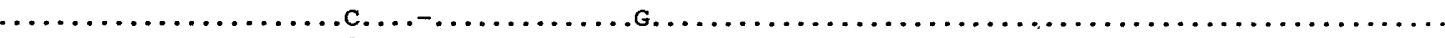

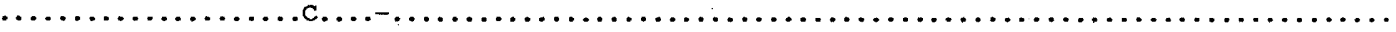

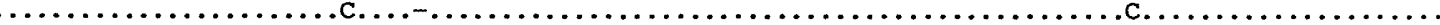

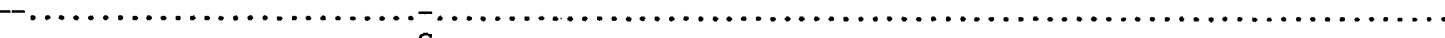

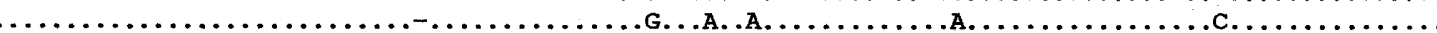
CTGAATTCCCCAGACCTGTTTGTGTTGGA. GGCTTTCAATGTGGACTGTGGTGTATTCAGAACCATGCTGGCTCTCCCATTTGAGGCCTGGTCTGAGAAA

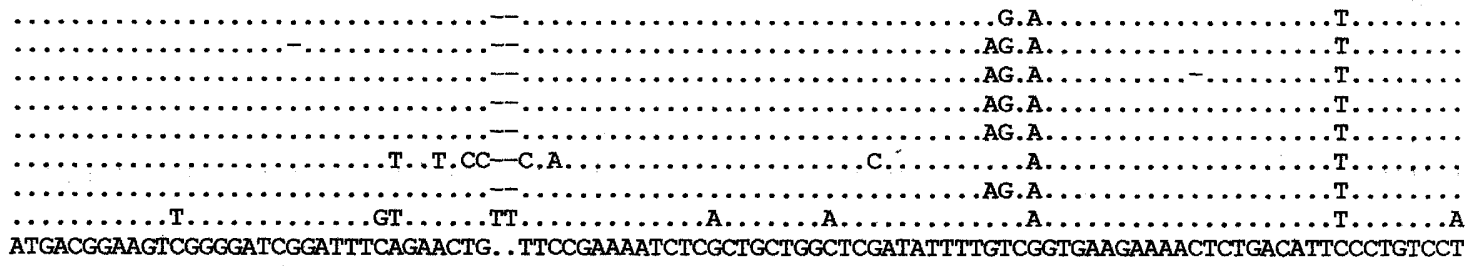

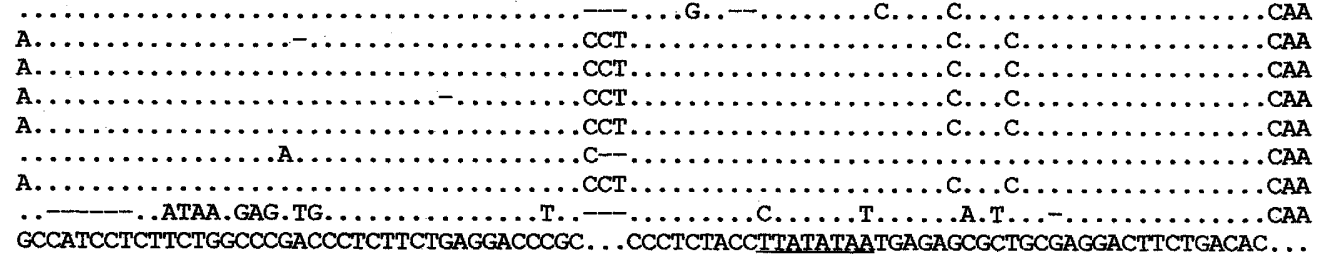

Figure 4 (See facing page for legend.) 
FÖRNZLER ET AL.
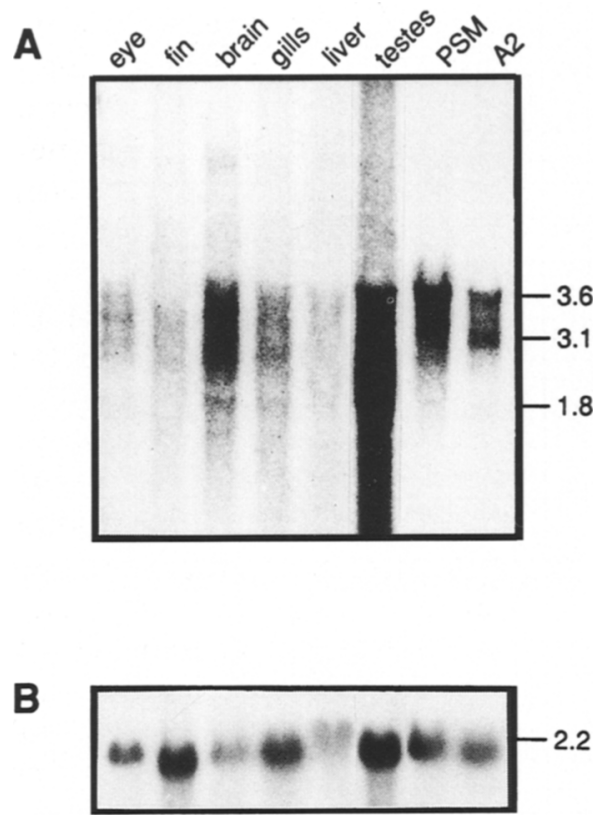

Figure 5 Expression of transcripts from the D2 3.5-kb EcoRI fragment. RNA from different organs and two Xiphophorus cell lines was isolated and blotted onto a nylon filter. $(A)$ The blot was hybridized with the 3.5-kb EcoRI fragment from phage D2 and washed with $0.25 \times \mathrm{SSC}, 1 \% \mathrm{SDS}$, at $65^{\circ} \mathrm{C}$. (B) After stripping, the filter was rehybridized with a Xiphophorus $\beta$-actin probe and washed with $0.2 \times$ SSC, $1 \%$ SDS, at $65^{\circ} \mathrm{C}$.

tional evidence comes from a closely related partial cDNA, which we isolated from PSM cells, that contains at least six zinc fingers (D. Förnzler, unpubl.).

Clustered krüppel zinc finger genes have been described for several chromosomes in humans, for example, for chromosome 10 (Tunnacliffe et al. 1993), chromosome 11 (Saleh et al. 1992), chromosome 16 (Cannizzaro et al. 1993), chromosome 19 (Lichter et al. 1992; Bellefroid et al. 1993), and in mice on chromosome 17 (Crossley and Little 1991). Clustered organization is also very common for other zinc finger genes and seems often to be associated with chromosomal regions involved in recurrent chromosomal aberrations such as deletions, translocations, and fragile sites leading to different neoplasias (Hübner et al. 1991; Lichter et al. 1992).

Surprisingly, the second transcription unit of the $D$ locus, which lies downstream of the promoter homologous to the Xmrk oncogene, encodes a completely unrelated protein. Structure predictions do not show any known motifs within the putative gene product HASI and thus give no hints as to what functional role this protein might play. However, the translated sequence shows a very high degree of similarity to a hypothetical protein from C. elegans. The high degree of conservation throughout evolution, at least in a domain of the molecule encompassing more than one-third of the ORF, and the fairly specific expression in Xiphophorus suggests a functional role for this protein and evokes the speculation that this new gene is also conserved in higher vertebrates. However, it is interesting to note that there is no evidence for an amplification of this gene in C. elegans, at least not in a clustered arrangement, which we find in Xiphophorus.

To our knowledge, there is no report so far about an amplified gene cluster containing two genes, which are structurally and probably also functionally completely different. The $D$ gene cluster is composed of one krüppel-type zinc fin-
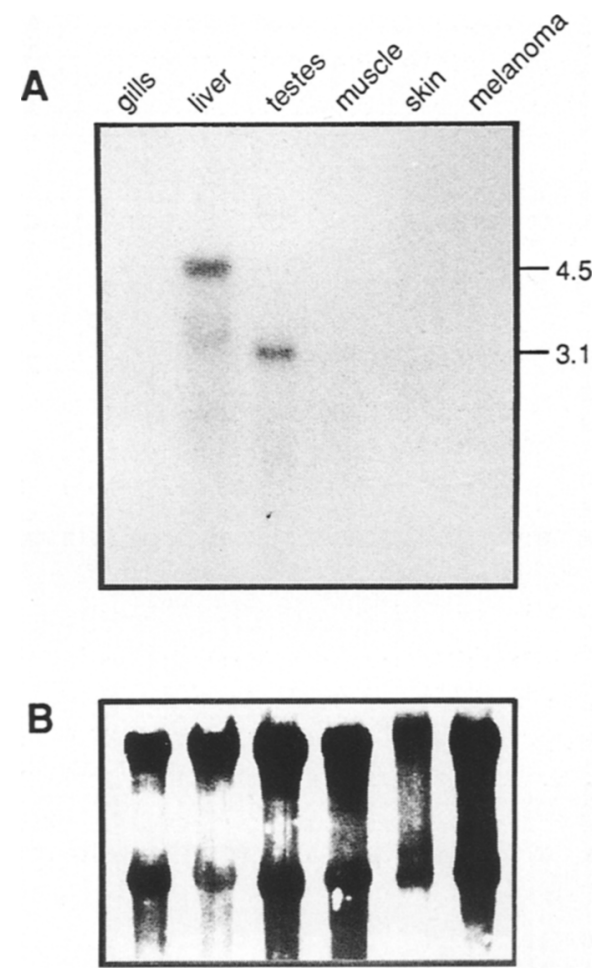

Figure 6 Expression of transcripts from the D2 2.1-kb EcoRI fragment. RNA from different organs was isolated and blotted onto a nylon filter. $(A)$ The blot was hybridized with the $2.1-\mathrm{kb}$ EcoRI fragment from phage D2 and washed with $0.2 \times$ SSC, $1 \%$ SDS, at $64^{\circ} \mathrm{C}$. (B) Methylene blue stain of the filter membrane. 
UNUSUAL ORGANIZATION OF A GENE CLUSTER IN FISH

A

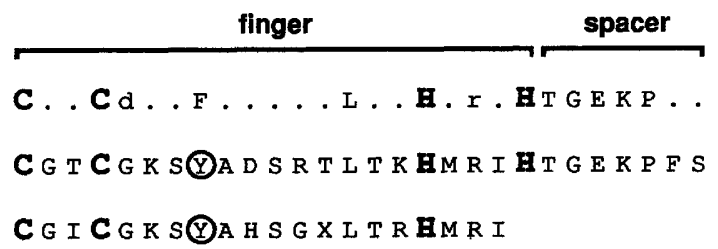

B

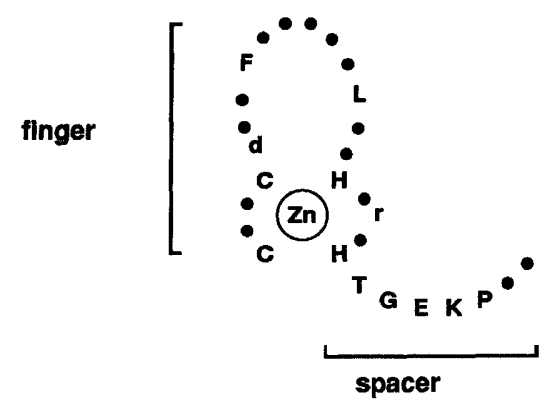

Figure $7 \quad D$ gene zinc finger. (A) Comparison between the krüppel zinc finger consensus sequence and the translated genomic $D$ gene sequence. The amino acids shown in bold determine the structure; uppercase letters in the consensus sequence indicate highly conserved residues. Tyrosine residues deviating from the consensus sequence are circled. (B) Hypothetical zinc finger structure with the cysteine and histidine residues coordinating a zinc ion.

ger gene followed by the gene called HASI, that lacks any structural homology to zinc finger genes. It remains to be investigated whether there is any functional correlation between these two genes.

The $D$ locus zinc finger probe has detected signals in nearly all Xiphophorus tissues investigated, including melanomas, as well as in the cell lines PSM and A2, and revealed several transcripts of different sizes. This could be attributed to alternative splicing, which is also found in other zinc finger genes of this type such as WT-1 (Haber et al. 1991) and HZF16 (Saleh et al. 1993). However, it is possible, that under the experimental conditions of the Northern blot analysis we have picked up closely related members of the extended krüppel zinc finger gene family, the number of which is estimated to be $>100$ in the vertebrate genome (Bellefroid et al. 1989; Hoovers et al. 1992).

In contrast, the $D$ gene $H A S I$, which contributed its promoter to the Xmrk oncogene, shows a very restricted pattern of expression: A $4.5-\mathrm{kb}$ transcript was found in liver and a 3.1-kb transcript in testes. The different transcripts could be explained similar as for the zinc finger gene above representing either differential splicing products or two different, closely related genes. Surprisingly, only in 1 of 10 melanomas krüppel consensus investigated a HASI transcript of 2.2 $\mathrm{kb}$ could be found. This is in obvious contrast to the Xmrk oncogene, which has an almost identical 5'upstream region. It is expressed in all malignant melanomas of Xiphophorus hybrids at high levels (Wittbrodt et al. 1989). So far, we could not detect expression of the oncogene in any nonmalignant tissue. Thus, there are unexpected differences in expression patterns between the oncogenic $\mathrm{X} m r$ k and HASI. It is highly unlikely that an as yet unidentified $D$ gene is expressed in the same tissue as the $\mathrm{X} m r k$ oncogene, as our cDNA is $98 \%$ identical to the corresponding genomic region over the 450 bp analyzed thus far, which suggests that we detect all HASI transcripts with such a probe. One possible explanation is that given there is variation in the $D$ locus promoters, sequence differences in the Xmrk oncogene promoter can account for the different transcriptional regulation. An alternative is that the melanoma specific transcriptional activation of the $\mathrm{X} m r k$ oncogene requires additional regulatory elements further 3 ', which are not found in the $D$ locus. In this context it is important to mention that an enhancer has been described in the first intron of the EGF receptor gene (Maekawa et al. 1989; Haley and Waterfield 1991) to which Xmrk is closely related and that the Xmrk oncogene and proto-oncogene are structurally different in this region (Woolcock et al. 1994; J. Altschmied, J. Duschl, and M. Schartl, unpubl.). To answer these questions it will be important to compare the transcriptional activity of the various $D$ locus promoters in functional assays in the future.

\section{METHODS}

\section{Experimental Animals}

All fish used in this study were bred under standard conditions (Kallman 1975) in the aquarium of the Biocenter at Würzburg University. Different genotypes of $X$. maculatus (Rio Jamapa) bearing various Xmrk alleles (distinguishable by specific macromelanophore patterns) were analyzed: 
FÖRNZLER ET AL.

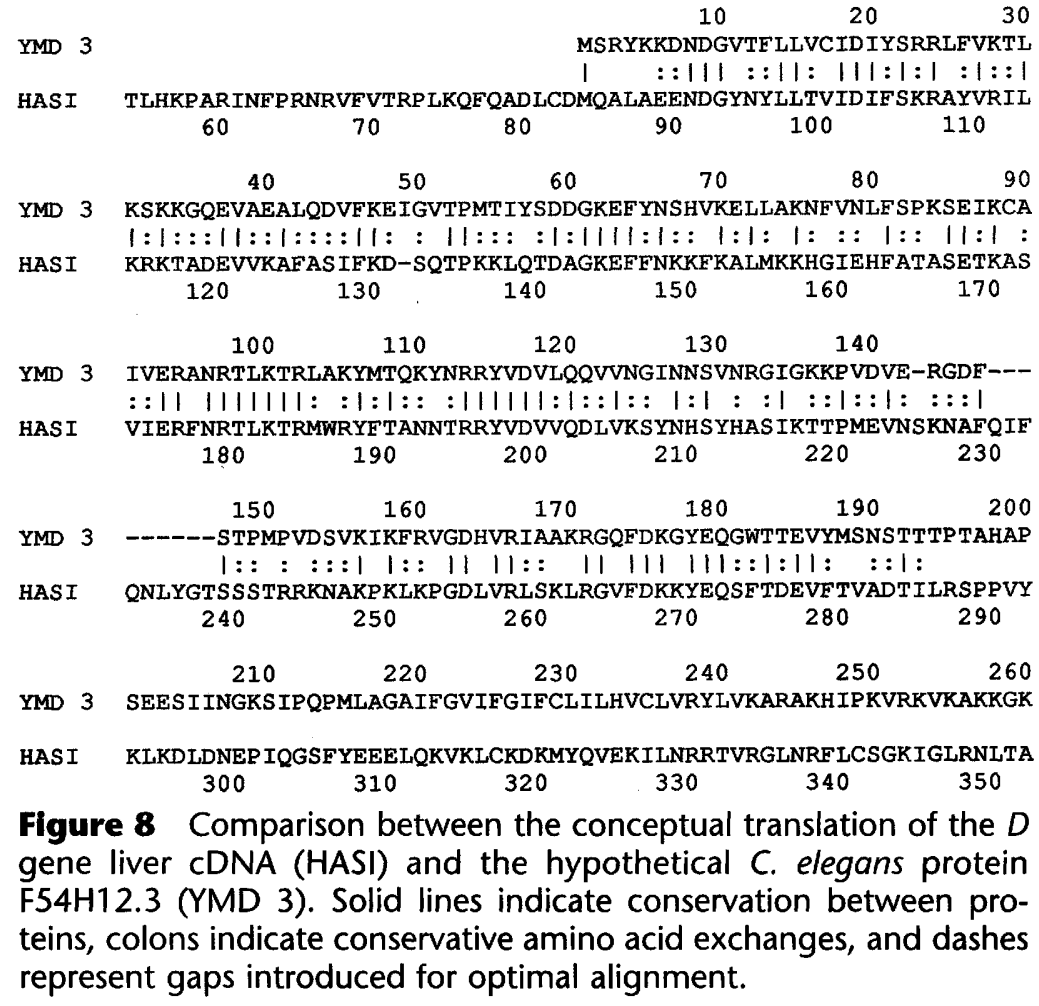

( $S d$ ) spotted dorsal, X-chromosomal; (Sr) striped, Y-chromosomal; (Sp) spotted, X-chromosomal. X. helleri III (Rio Lancetilla) does not carry any oncogenic Xmrk locus.

\section{Cell Lines and Culture}

The embryonic epithelial cell line A2 (Kuhn et al. 1979) and melanoma cell line PSM (Wakamatsu 1981), both from Xiphophorus, were cultured under conditions described (Mäueler et al. 1988). After reaching confluency, cells were harvested and used for preparation of DNA and RNA.

\section{DNA Isolation and Southern Hybridizations}

DNA from pooled organs of $X$. maculatus and $X$. helleri as well as PSM- and A2-DNA was extracted essentially as described (Schartl et al. 1995). Plasmid and phage DNA extractions were done according to standard methods. After complete restriction digestion, DNA was separated on $0.8 \%$ agarose gels and transferred to nylon membranes. DNA fragments to be used as hybridization probes were gel purified with QIAEX (Qiagen, Hilden) and were randomly labeled with $\left[\alpha^{-}{ }^{32} \mathrm{P}\right] \mathrm{dCTP}$ using the protocol of Feinberg and Vogelstein (1983). Filters were hybridized in $50 \mathrm{~mm}$ TrisCl (pH 7.5), $5 \times$ Denhardt's solution, $5 \times$ SSC, $1 \%$ SDS, $0.1 \%$ sodium-pyrophosphate, and $50 \%$ formamide at $42^{\circ} \mathrm{C}$ overnight. After the hybridization, filters were washed twice in $1 \%$ SDS containing various concentrations of SSC at the temperatures indicated for $30 \mathrm{~min}$ each time. The membranes were rinsed with $2 \times$ SSC and exposed wet to film. The same filters were reused for different probes after stripping with $0.01 \times \mathrm{SSC}$, $1 \% \mathrm{SDS}$, at $90^{\circ} \mathrm{C}$ for $30 \mathrm{~min}$.

\section{RNA Isolation and Northern Hybridizations}

Total RNA was isolated by the $\mathrm{LiCl}$ procedure (LeMeur et al. 1981). Northern blots and hybridizations have been done as described (Mäueler et al. 1988) using DNA probes that were labeled as described above. For size calibration, an RNA ladder (BRL, Bethesda) was included. To control for equal loading, filters were stained for $15 \mathrm{~min}$ at room temperature with $0.04 \%$ methylene blue and destained with three changes of $25 \%$ ethanol. Alternatively, the filters were hybridized with the ubiquitously expressed Xiphophorus $\beta$-actin gene (gift from R.Walter, Southwest Texas State University, San Marcos).

\section{Library Screening}

Libraries were screened according to standard procedures; hybridization and washing were done as described for the Southern blot analyses. To isolate genomic $D$ sequences, a library from $X$. maculatus $S r^{\prime \prime} / D r L i$ in EMBL 4 was screened with a $0.3-\mathrm{kb}$ Xmrk oncogene promoter fragment, which had been described previously to match the corresponding $D$ sequences (Adam et al. 1993). The filters were washed with $0.1 \times$ SSC, $1 \%$ SDS, at $68^{\circ} \mathrm{C}$. By screening a total of $10^{6}$ plaques, 24 doublepositive phages were isolated, which showed four distinct restriction patterns. One phage from each class (D2, D8, D16, D38) was characterized further.

To isolate the $D$ gene, an oligo(dT) random-primed, custom-made liver cDNA library in $\lambda$ ZAPII (Clonetech) from poly $(\mathrm{A})^{+}$RNA of $X$. maculatus (Genotype: $S d, S r, S p$ ) was used. Recombinant library clones $\left(10^{6}\right)$ were screened with the 2.1-kb EcoRI fragment derived from the genomic clone D2. The filters were washed with $0.5 \times$ SSC, $1 \%$ SDS, at $62^{\circ} \mathrm{C}$. One phage clone was isolated and characterized further. Restriction fragments from phages were subcloned into Bluescript IIKS(+) (Stratagene, La Jolla).

\section{Enzymatic DNA Amplification of $D$ gene Promoters}

PCR amplification was performed in a $50 \mu \mathrm{l}$ volume with $200 \mathrm{ng}$ of genomic DNA or $500 \mathrm{pg}$ of purified phage DNA as template and 1.25 units of Taq polymerase. $100 \mathrm{mM}$ TrisCl ( $\mathrm{pH} 9.0$ at room temperature), $50 \mathrm{~mm} \mathrm{KCl}, 1.5 \mathrm{~mm}$ $\mathrm{MgCl}_{2}, 0.1 \%$ gelatin, and $1 \%$ Triton X-100. Amplification was performed for 30 cycles with $55^{\circ} \mathrm{C}$ as annealing temperature for the initial five cycles and $70^{\circ} \mathrm{C}$ for the remainder of the PCR. The primers used were deduced from the phage D2 and had the following sequences: 5'CTCGGATCCCTCAAGGCAGACTGG-3' and 5'CTCCTCGAGGTTTGGTGTCAGAAGTCC-3'. The PCR products were gel purified with QIAEX (Qiagen, Hilden) 
and subcloned into pUC 18 using the SureClone ligation kit (Pharmacia, Freiburg).

\section{DNA Sequencing and Sequence Analysis}

Double-stranded DNA sequencing was performed using the TAQence and Sequenase kits (U.S. Biochemical) and $\left[\alpha-{ }^{35} S\right]$ dATP according to the manufacturers' recommendations. Sequence assembly and comparison was done using the UWGCG program package (Program Manual for the Wisconsin Package, version 8, September 1994, Genetics Computer Group, Madison, WI). Data base searches were done using the BLAST routine (Altschul et al. 1990). Parsimony analyses were done with the DNAPARS program of the PHYLIP package, version 3.5c (Felsenstein 1989). Bootstraping (1000 replications) was done with SEQBOOT to generate multiple data sets and CONSENSE to obtain the majority rule consensus tree.

\section{Chromosome Preparation}

Mitotic chromosomes were prepared directly from pooled spleen, gills, and cephalic kidney cells after exposing the fish to a $0.03 \%$ solution of colchicine for $10-12 \mathrm{hr}$. (Nanda et al. 1993). Meiotic chromosomes were obtained from testicular cells according to the method of Haaf and Schmid (1984).

\section{FISH}

The 3.5-kb EcoRI fragment from the phage D2 was labeled with biotin-16-dUTP (Boehringer Mannheim) by standard nick translation. The labeled DNA was separated from unincorporated nucleotides by chromatography through a Sephadex G-50 spun column. Biotinylated probe (30 ng) was mixed with $5 \mu \mathrm{g}$ of sonicated, denatured calf thymus DNA and precipitated with ethanol. The DNA precipitate was resuspended in $\mathbf{1 5} \mu \mathrm{l}$ of hybridization mixture $(50 \%$ formamide, $2 \times \mathrm{SSC}, 10 \%$ dextran sulfate), denatured at $75^{\circ} \mathrm{C}$ for $10 \mathrm{~min}$, and quickly chilled on ice. The probe was then applied to denatured chromosomes (slides treated at $70^{\circ} \mathrm{C}$ for 2 min with $70 \%$ formamide, $2 \times \mathrm{SSC}$ at $\mathrm{pH} 7.0$ ), and hybridization was performed in a moist chamber at $37^{\circ} \mathrm{C}$. After overnight incubation, the coverslips were removed and the slides were washed three times in $50 \%$ formamide, $2 \times \mathrm{SSC}$, at $45^{\circ} \mathrm{C}$ followed by two washes at $55^{\circ} \mathrm{C}$ in $0.2 \times$ SSC. Detection was accomplished by incubation of the slides with fluoresceinated avidin. The signal was enhanced by incubation with biotinylated goat-antiavidin (Vector Laboratories, Burlingame, CA) followed by an incubation with fluoresceinated avidin. Slides were then counterstained with DAPI and propidium iodide and mounted in antifade solution. The hybridization signals on the chromosomes were analyzed under a Zeiss Axiophot fluorescence microscope equipped with appropriate filters. Kodak Ektachrome 320 ASA color slide film was used for microphotography.

\section{ACKNOWLEDGMENTS}

We thank R. Walter for the gift of the Xiphophorus $\beta$-actin probe, L. Ditzel for help in mapping the $D$ phages, J.
Duschl for photographic artwork, the aquarium staff for the breeding of the fish, and M. Gessler and B. Weber for critically reading the manuscript. This work was supported by grants to $M$. Schartl supplied by the Deutsche Forschungsgemeinschaft through SFB 165 ("Genexpression in Vertebraten"), Graduiertenkolleg "Regulation des Zellwachstums", from the European Union (EU) (grants BIO2CT-930430 and CI1-CT94-0021) and the Fonds der Chemischen Industrie and by a grant to M. Schmid supplied by the EEC (grant AIR2-CT93-1543). The sequences of the putative $D$ gene promoters, the zinc finger coding region, and the HASI cDNA have been submitted to GenBank under the following accession numbers: U43114 (D2), U43115 (D8), U43116 (D16), U43117 (D38), U43118 (G4), U43119 (G16), U43120 (G29), U43113 (zinc finger), and U43331 (HASI cDNA).

The publication costs of this article were defrayed in part by payment of page charges. This article must therefore be hereby marked "advertisement" in accordance with 18 USC section 1734 solely to indicate this fact.

\section{NOTE ADDED IN PROOF}

Further sequencing has revealed the presence of a third open reading frame of 251 amino acids within the $D$ locus with no homologies to any known protein. This could represent another coding exon of $H A S I$.

\section{REFERENCES}

Adam, D., W. Mäueler, and M. Schartl. 1991. Transcriptional activation of the melanoma inducing Xmrk oncogene in Xiphophorus. Oncogene 6: 73-80.

Adam, D., N. Dimitrijevic, and M. Schartl. 1993. Tumor suppression in Xiphophorus by an accidentally aquired promotor. Science 259: 816-819.

Altschmied, J. and M. Schartl. 1994. Genetics and molecular biology of tumour formation in Xiphophorus. In The legacy of cell fusion (ed. S. Gordon), pp. 199-214. Oxford University Press, Oxford, UK.

Altschul, S.F., W. Gish, W. Miller, E.W. Myers, and D.J. Lipman. 1990. Basic local alignment search tool. J. Mol. Biol. 215: 403-410.

Bellefroid, E.J., P.J. Lecocq, A. Benhida, D.A. Poncelet, A. Belayew, and J.A. Martial. 1989. The human genome contains hundreds of genes coding for finger proteins of the krüppel type. DNA 8: 377-387.

Bellefroid, E.J., D.A. Poncelet, P.J. Lecocq, O. Revelant, and J.A. Martial. 1991. The evolutionarily conserved Krüppel-asociated box domain defines a subfamily of eukaryotic multifingered proteins. Proc. Natl. Acad. Sci. 88: $3608-3612$.

Bellefroid, E.J., J.C. Marine, T. Ried, P.J. Lecocq, M. Riviere, C. Amemiya, D.A. Poncelet, P.G. Coulie, P. deJong, C. Szpierer, D.C. Ward, and J.A. Martial. 1993. Clustered organization of homologous KRAB zinc-finger 


\section{FÖRNZLER ET AL.}

genes with enhanced expression in human $\mathrm{T}$ lymphoid cells. EMBO J. 12: 1363-1374.

Cannizzaro, L.A., M.M. Aronson, and H.J. Thiesen. 1993. Human zinc finger gene ZNF23 (Kox16) maps to a zinc finger gene cluster on chromosome 16q22, and ZNF32 (Kox30) to chromosome region 10q23-q24. Hum. Genet. 91: $383-385$.

Crossley, P.H. and P.F.R. Little. 1991. A cluster of related zinc finger protein genes is deleted in the mouse embryonic lethal mutation $t^{w 18}$. Proc. Natl. Acad. Sci. 88: 7923-7927.

Feinberg, A.P. and B. Vogelstein. 1983. A technique for radiolabeling DNA restriction endonuclease fragments to high specific activity. Anal. Biochem. 132: 6-13.

Felsenstein, J. 1989. PHYLIP phylogeny inference package (version 3.2). Cladistics 5: 164-166.

Haaf, T. and M. Schmid. 1984. An early stage of ZW/ZZ sex chromosome differentiation in Poecilia sphenops var. melanistica (Poeciliidae, Cyprinodontiformes).

Chromosoma 89: 37-41.

Haber, D.A., R.L. Sohn, A.J. Buckler, J. Pelletier, K.M. Call, and D.E. Housman. 1991. Alternative splicing and genomic structure of the Wilms tumor gene WT1. Proc. Natl. Acad. Sci. 88: 9618-9622.

Haley, J. and M.D. Waterfield. 1991. Contributory effects of de novo transcription and premature transcript termination in the regulation of human epidermal growth factor receptor proto-oncogene RNA synthesis. J. Biol. Chem. 266: 1746-1753.

Hoovers, J.M.N., M. Mannens, R. John, J. Bliek, V. Van Heyningen, D.J. Porteous, N.J. Leschot, A. Westerveld, and P.F.R. Little. 1992. High resolution localization of 69 potential human zinc finger protein genes: A number are clustered. Genomics 12: 254-263.

Hübner, K., T. Druck, C.M. Croce, and H.J. Thiessen. 1991. Twenty-seven nonoverlapping zinc finger cDNAs from human $T$ cells map to nine different chromosomes with apparent clustering. Am. J. Hum. Genet. 48: $726-740$.

Jacobs, G.H. 1992. Determination of the base recognition positions of zinc fingers from sequence analysis. EMBO J. 11: 4507-4517.

Kallman, K.D. 1975. The platyfish, Xiphophorus maculatus. In Vertebrates of genetic interest (ed. R.C. King), pp. 81-132. Plenum Press, New York.

Kuhn, C., U. Vielkind, and F. Anders. 1979. Cell cultures derived from embryos and melanoma of poeciliid fish. In Vitro 15: 537-544.

LeMeur, M., N. Glanville, J.L. Mandel, P. Gerlinger, R. Palmiter, and P. Chambon. 1981. The ovalbumin gene family: Control of $\mathrm{X}$ and $\mathrm{Y}$ gene transcription and mRNA accumulation. Cell 23: 561-571.

Lichter, P., P. Bray, T. Ried, I.B. Dawid, and D.C. Ward. 1992. Clustering of $\mathrm{C}_{2}-\mathrm{H}_{2}$ zinc finger motif sequences within telomeric and fragile site regions of human chromosomes. Genomics 13: 999-1007.

Maekawa, T., F. Imamoto, G.T. Merlino, I. Pastan, and S. Ishii. 1989. Cooperative function of two separate enhancers of the human epidermal growth factor receptor proto-oncogene. J. Biol. Chem. 264: 5488-5494.

Mäueler, W., F. Raulf, and M. Schartl. 1988. Expression of proto-oncogenes in embryonic, adult, and transformed tissue of Xiphophorus (Teleostei: Poeciliidae). Oncogene 2: 421-430.

Nanda, I., M. Schartl, J.T. Epplen, W. Feichtinger, and M. Schmid. 1993. Primitive sex chromosomes in poeciliid fishes harbor simple repetitive DNA sequences. J. Ex. Zoology 265: 301-308.

Saleh, M., L. Selleri, P.F.R. Little, and G.A. Evans. 1992. Isolation and expression of linked zinc finger gene clusters on human chromosome 11q. Genomics 14: 970-978.

Saleh, A., L. Selleri, and G.A. Evans. 1993. A novel zinc finger gene on human chromosome 1qter that is alternatively spliced in human tissues and cell lines. Am. J. Hum. Genet. 52: 192-203.

Santoro, M., F. Carlomagno, A. Romano, D.P. Bottaro, N.A. Dathan, M. Grieco, A. Fusco, G. Vecchio, B. Matoskova, M.H. Krauss, and P.P. Di Fiore. 1995. Activation of RET as a dominant transforming gene by germline mutations of MEN2A and MEN2B. Science 267: 381-383.

Schartl, M. 1995. Platyfish and swordtails: A genetic system for the analysis of molecular mechanisms in tumor formation. Trends Genet. 11: 185-189.

Schartl, M., B. Wilde, I. Schlupp, and J. Parzefall. 1996. Evolutionary origin of a parthenoform, the amazon molly $P$. formosa, on the basis of molecular genealogy. Evolution 49: 827-835.

Schuh, R., W. Aicher, U. Gaul, S. Cote, A. Preiss, D. Maier, E. Seifert, U. Nauber, C. Schrop̈der, R. Kemler, and $H$. Jäckle. 1986. A conserved family of nuclear proteins containing structural elements of the finger protein encoded by krüppel, a Drosophila segmentation gene. Cell 47: 1025-1032.

Tunnacliffe, A., L. Liu, J.K. Moore, M.A. Leversha, M.S. Jackson, L. Papi, M.A. Ferguson-Smith, H.J. Thiesen, and B.A.J. Ponder. 1993. Duplicated KOX zinc finger gene clusters flank the centromere of human chromosome 10: Evidence for a pericentric inversion during primate evolution. Nucleic Acids Res. 21: 1409-1417.

Villa, A., C. Patrosso, I. Biunno, A. Frattini, M. Repetto, 
M. Mostardini, G. Evans, L. Susani, D. Strina, E. Redolfi et al. 1992. Isolation of a zinc finger motif (ZNF75) mapping on chromosome Xq26. Genomics 13: $1231-1236$.

Villa, A., I. Zucchi, G. Pilia, D. Strina, L. Susani, F. Morali, C. Patrosso, A. Frattini, F. Lucchini, M. Repetto et al. 1993. ZNF75: Isolation of a cDNA clone of the KRAB zinc finger gene subfamily mapped in YACs $1 \mathrm{Mb}$ telomeric of HPRT. Genomics 18: 223-229.

Wakamatsu, Y. 1981. Establishment of a cell line from the platyfish-swordtail hybrid melanoma. Cancer Res. 41: $679-680$.

Wilson, R., R. Ainscough, K. Anderson, C. Baynes, M. Berks, J. Bonfield, J. Burton, M. Connell, T. Copsey, J. Cooper et al. 1994. 2.2 Mb of contiguous nucleotide sequence from chromosome III of C. elegans. Nature 368: $31-38$.

Wittbrodt, J., D. Adam, B. Malitschek, W. Mäueler, F. Raulf, A. Telling, S.M. Robertson, and M. Schartl. 1989. Novel putative receptor tyrosine kinase encoded by the melanoma-inducing $\mathrm{Tu}$ locus in Xiphophorus. Nature 341: $415-421$.

Woolcock, B.W., B.M. Schmidt, K.D. Kallman, and J.R. Vielkind. 1994. Differences in transcription and promoters of Xmrk-1 and Xmrk-2 genes suggest a role for Xmrk-2 in pigment pattern development in the platyfish Xiphophorus maculatus. Cell, Growth Differ. 5: 575-583.

Received September 5, 1995; accepted in revised form January $5,1996$. 


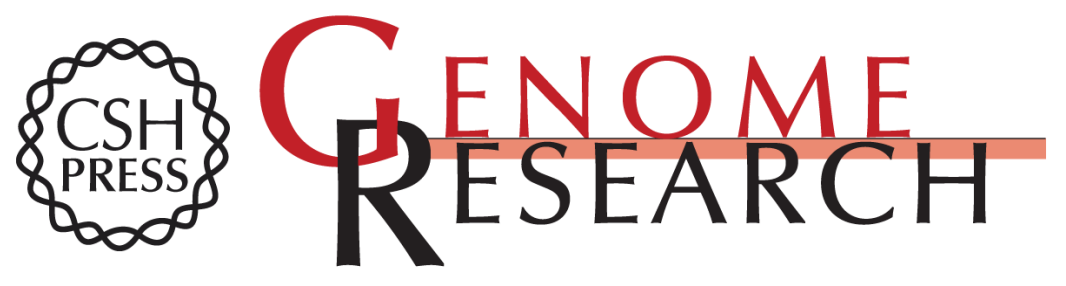

\section{The Xmrk oncogene promoter is derived from a novel amplified locus of unusual organization.}

D Förnzler, J Altschmied, I Nanda, et al.

Genome Res. 1996 6: 102-113

Access the most recent version at doi:10.1101/gr.6.2.102

References This article cites 35 articles, 9 of which can be accessed free at:

http://genome.cshlp.org/content/6/2/102.full.html\#ref-list-1

\section{License}

Email Alerting Receive free email alerts when new articles cite this article - sign up in the box at the Service top right corner of the article or click here.

\section{Affordable, Accurate Sequencing.}

To subscribe to Genome Research go to:

https://genome.cshlp.org/subscriptions 